
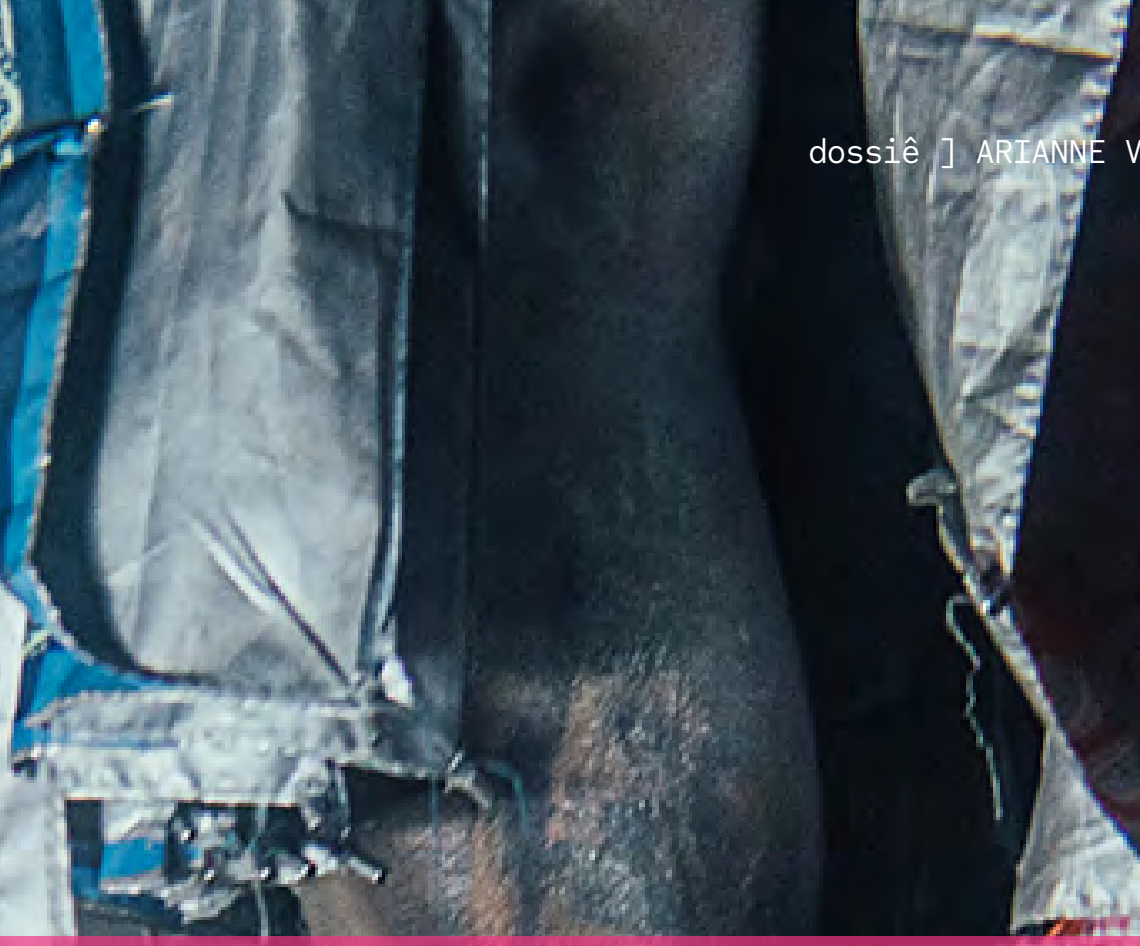

dossiê ] ARIANNE VITALE CARDOSO RENATO BOLELLI REBOUÇAS
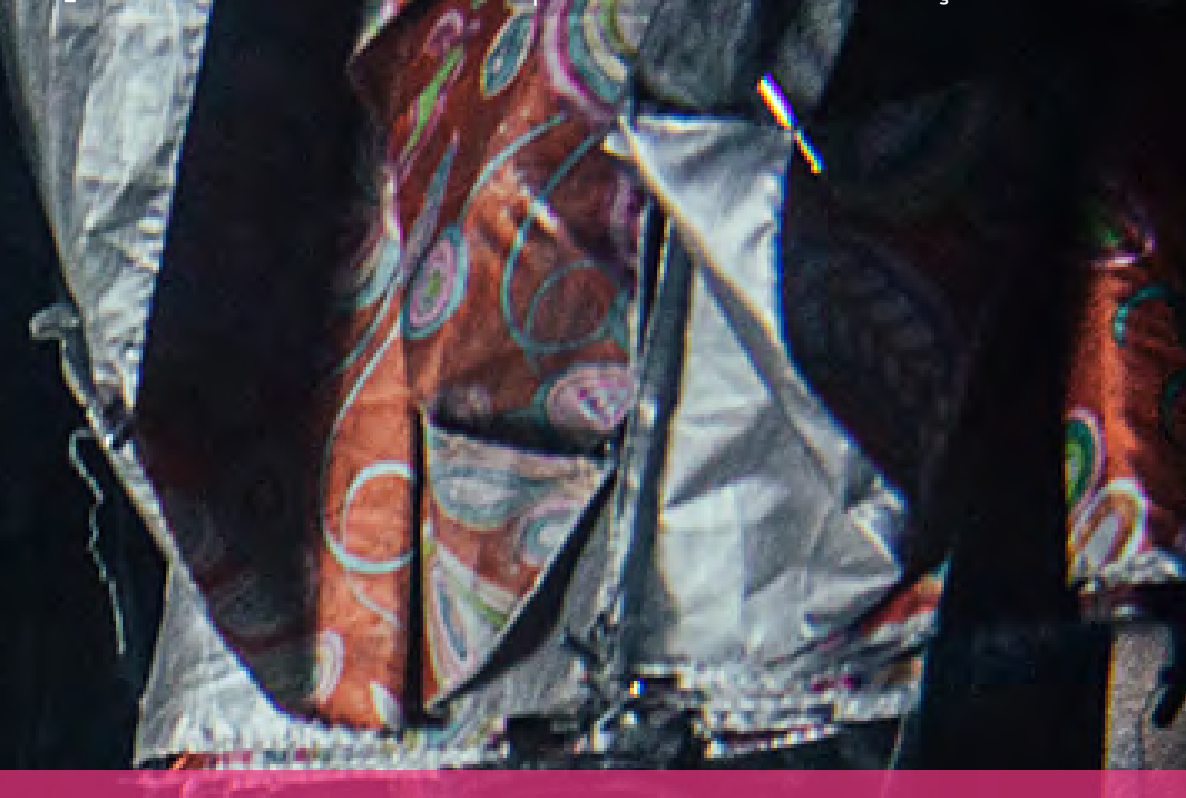

\title{
Vestir a invenção: poéticas de guerrilha artística em ações coletivas
}

Wearing the invention: poetics of artistic guerrilla in collective actions 
ARIANNE VITALE CARDOSO'

ORCID: https://orcid.org/0000-0002-1916-9573

RENATO BOLELLI REBOUÇAS ${ }^{2}$

ORCID: http://orcid.org/0000-0001-8454-3720

[resumo] 0 artigo apresenta práticas contemporâneas para a criação de indumentárias que se apropriam da materialidade para criar dispositivos, nas quais os papéis do criador/ designer e do performer se misturam e contaminam. Para delinear esses atravessamentos, apresentaremos a construção da obra INVENÇÃO, desenvolvida como uma ação coletiva integrante do projeto "Vista a sua Existência", idealizado pela Usina da Alegria Planetária (UAP) em conjunto com diversos artistas envolvidos no processo de forma dinâmica. 0 resultado da obra, em constante movimento, desloca seu foco para o relacionamento direto com a experiência do fazer e para a hibridez de linguagens e suportes, ativando dimensões políticas em escala urbana.

[palavras-chave] Figurino. Performance. Arte pública. Coletividade. Materialidade.

[abstract] This article presents contemporary practices for the creation of costumes which appropriate the materiality to create devices, mixing and contaminating the roles of the creator/designer and the performer. To expose these crossings, we will present the construction of the project INVENÇÃO, which was developed as a collective action connected to the project Wear Your Existence, conceived by the UAP Art Platform in a conjoined work process between several artists. The artistic result is in constant movement, shifting its focus to the direct relationship with the experience of doing whose result occurs in the hybridity of languages and supports, activating urban and political dimensions.

[keywords] Costume. Performance art. Public art. Collectivity. Materiality.

Recebido em: 21-03-2019.

Aprovado em: 05-06-2019.

\footnotetext{
1 Mestre em Artes pela USP. Doutoranda no PPGAC-USP.

E-mail: ariannevc@ahotmail.com. Lattes: http://lattes.cnpq.br/2357073595773689.

2 Mestre em Artes pela USP. Doutorando no PPGAC-USP.

E-mail: bolellireboucas@gmail.com. Lattes: http://lattes.cnpq.br/9406647049065152.
} 


\section{Introdução}

A visualidade da cena contemporânea tem se expandido em estratégias de ação híbrida nas quais os papéis do criador/designer e do performer se misturam e contaminam, assim como a relação com as matérias e os materiais, que se tornam impulso de ação para o corpo em estratégias não mais pautadas na concepção do design, mas nos elementos que são manipulados durante a dinâmica efêmera do fazer artístico.

Estas práticas, que se manifestam em diferentes linguagens, têm ampliado o processo de criação do figurino/indumentária, borrando assim os limites entre artes cênicas, arte visuais, a moda e os estudos da performance, dando origem a obras que versam sobre a imagem e o uso/comportamento/ação diante do fazer e da materialidade presente nos elementos utilizados. Assim, temas como a composição da personagem, a coerência com um texto ou narrativa preexistentes e a funcionalidade/viabilidade com relação ao ator/atriz/ performer dão lugar a outras investigações, como a produção de um sentido de work in process (o processo de criação é que dá origem à imagem/resultado), a busca/coleta/escolha de materiais como trajetória narrativa e as possibilidades oferecidas pela criação em relação ao corpo e ao espaço em que está inserido.

0 resultado da obra encontra-se em constante movimento, deslocando seu foco para o relacionamento direto com a experiência do fazer. A prática, neste sentido, abarca possíveis "erros" e torna-se caminho, percurso, ela mesma processo de criação e performance, pois exige presença e ação. Torna-se descoberta. Neste contexto, o fazer, muitas vezes coletivo, expandido, incentiva as relações entre diferentes realidades, gêneros, classes, áreas e grupos, versando entre o popular e o erudito, o artificial e o natural, a precariedade e a sofisticação, propondo a contaminação e a sobreposição de visualidades, estéticas e significações a partir dos repertórios individuais. Assim, cada participante inscreve, de diversas maneiras, o processo vivido no próprio corpo e, ainda, expõe seu corpo ressignificado.

A partir desta premissa, atravessaremos a construção da obra INVENÇÃO (figura 1), desenvolvida como uma ação coletiva integrante do projeto "Vista a sua Existência", idealizado pela Usina da Alegria Planetária (UAP) ${ }^{3}$, num trabalho que se deu em conjunto entre diversos artistas e colaboradores. Cada elemento participante da composição dessa obra apresenta-se como resultado de uma criação que perpassa os limites entre as linguagens e também o das autorias na compreensão e afirmação da arte como processo, para a efetivação de uma imagem manifestada através das trocas de materiais e sua transformação, além das afetividades expressadas em performances, fotografias e ações urbanas resultantes.

\footnotetext{
3 A Usina da Alegria Planetária (UAP) é uma plataforma de criação e pesquisa que, desde 2010, propõe a troca livre entre artistas. Oferece um espaço de experimentação e discussão deslocado da cidade, no qual a imersão junto à natureza possa oferecer alternativas à produção contemporânea. Desde 2012, seu Programa de Residência Artística recebe artistas brasileiros e estrangeiros para visitas, práticas compartilhadas e imersões, promovendo a interação entre o fazer e a construção de linguagem. Para saber mais: www.uap-residence.com.
} 
Chamamos este fazer de uma experiência de guerrilha, não apenas pelo imaginário político que ele carrega, mas sobretudo por seu processo de realização, baseado mais em táticas do que em estratégias, em procedimentos não convencionais perpetrados por grupos em detrimento dos indivíduos e caracterizado pela extrema mobilidade de seus combatentes/artistas.

FIGURA 1 - LAMBE-LAMBE COM A OBRA INVENÇÃO, PROCESSO CRIADO EM RESIDÊNCIA ARTÍSTICA NA UAP, 2014

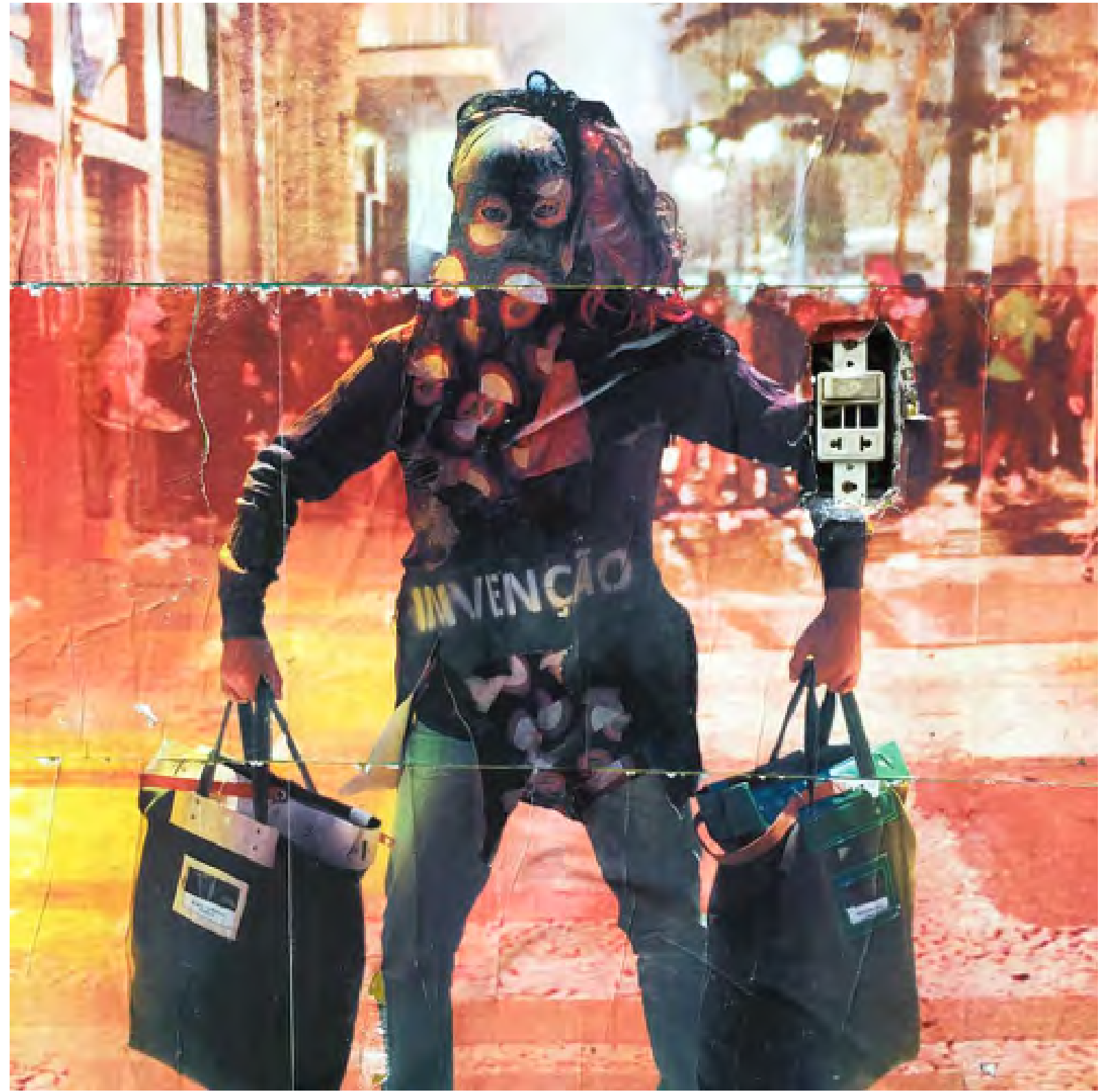

FONTE: LAVEZZARO, Andrea. Lambe-lambe INVENÇÃO vista a sua existência. 1 fotografia. 2014. Na imagem, performance de Renato Bolelli Rebouças, máscara de Arianne Vitale, capa e estêncil Renato Bolelli Rebouças, idealização de imagem de Kabila Aruanda, intervenção gráfica de Marx Deganelli. 
Processos de criação híbridos: a cena contemporânea expandida (ou camadas, camadas, camadas)

A trajetória que compõe a obra INVENÇÃO baseia-se na composição livre de fragmentos que atravessaram tempos e espaços variados, sendo produzida de maneira autoral e coletiva, reconfigurando-se e expandindo-se a cada nova etapa de criação/intervenção. Cada criador agregou ativamente ao resultado elementos e camadas não só materiais, mas também sensíveis, que transformam as imagens a cada operação realizada e os imaginários aos quais as associamos.

A proposta de trabalho iniciou-se numa colaboração entre os cenógrafos e figurinistas Arianne Vitale Cardoso e Renato Bolelli Rebouças em 2012, a partir de residências artísticas e da troca de fragmentos de materiais coletados por ambos em diferentes localidades: Berlim e São Paulo, respectivamente. A coleta de materiais usados/abandonados tem sido uma prática desenvolvida pelos artistas em suas pesquisas, e resultou na seleção de tecidos e outros elementos (como passamanarias, fitas, broches, botões e outros acabamentos) enviados para os dois locais como "cartas-surpresa" (figura 2). Cada artista, ao receber os materiais, criou elementos independentes, como a máscara e parte da indumentária utilizada em INVENÇÃO. As peças produzidas foram registradas e compartilhadas em fotografias entre os artistas.

FIGURA 2 - PACOTE ENVIADO PELO CORREIO DE BERLIM PARA A UAP COM DIVERSOS PEDAÇOS DE TECIDOS E PRECIOSIDADES, EM 2012

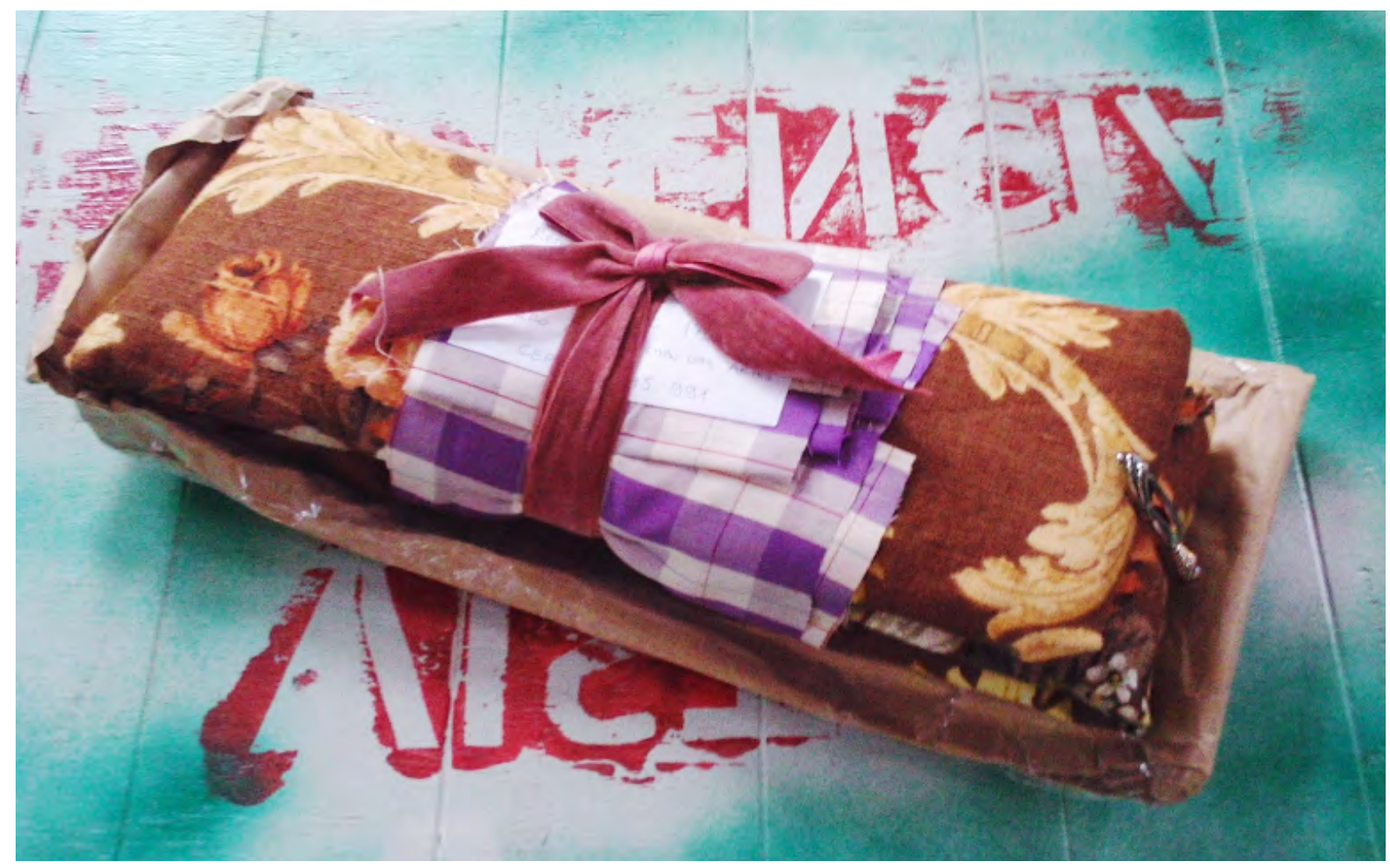

FONTE: REBOUÇAS, Renato Bolelli. Preciosidades do velho mundo. 1 fotografia. 2012. 
A máscara, criada por Cardoso, foi modelada apenas pela combinação do tecido com o látex, que é uma resina natural da borracha, aplicada diretamente com as mãos sobre o tecido em uma base de rosto de manequim. A técnica foi aprimorada a partir do uso do látex em experimentações sobre tecidos e peças de crochê que modelavam e davam forma às máscaras emborrachadas e aos adereços manufaturados, realizados em 2013 (figura 3), que resultaram na série de fotografias performáticas Upcycling Dream, apresentada no centro cultural Kunstraum Bethanien, em Berlim.

FIGURA 3 - MÁSCARA CRIADA NO ATELIER DE ARIANNE VITALE CARDOSO NA LENAU ST., BERLIM, EM 2012

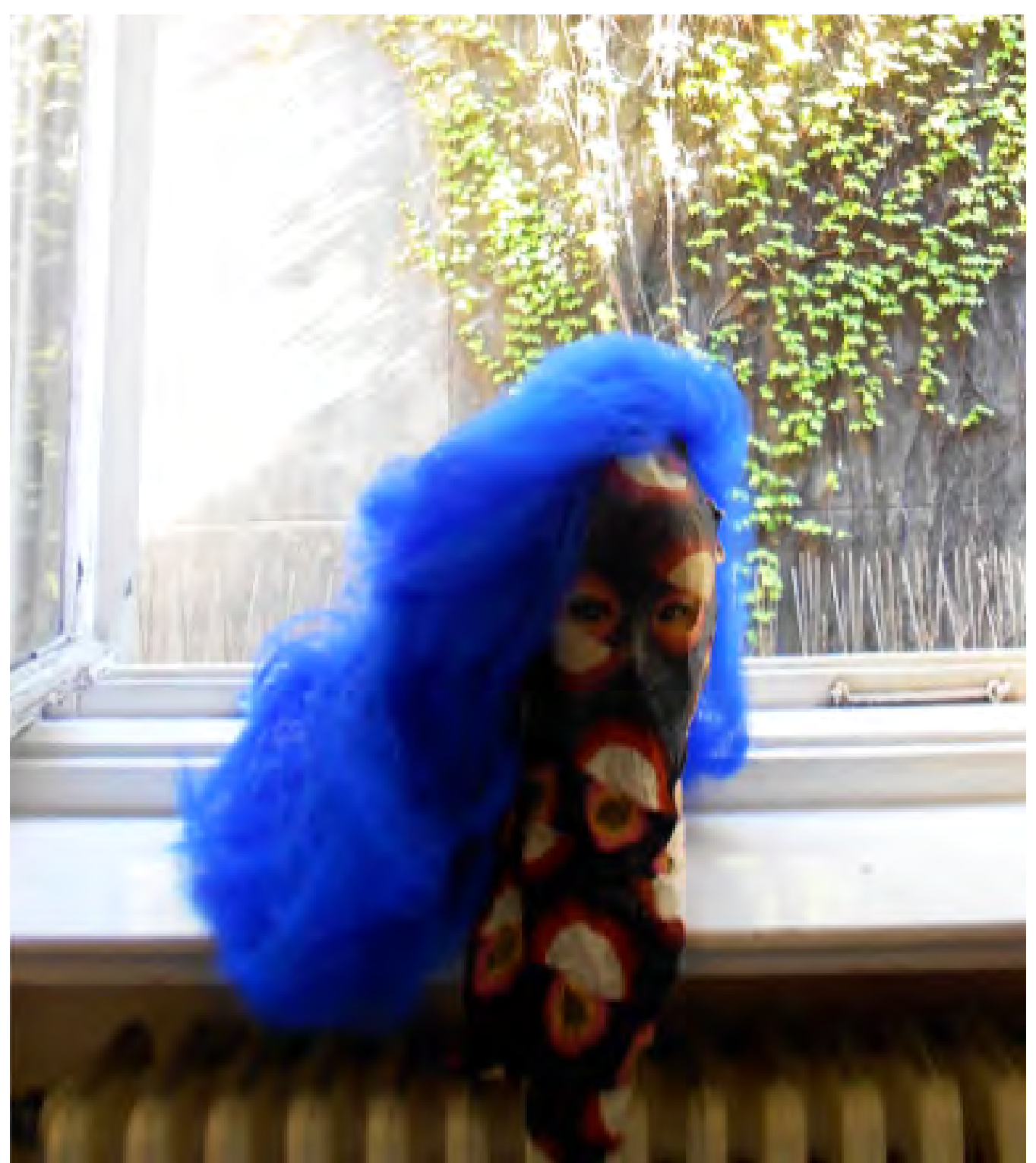

FONTE: CARDOSO, Arianne Vitale. Upcycling dream - máscara de látex com peruca azul. 1 fotografia. 2013. 
Já a peça criada por Bolelli Rebouças (figura 4) a partir dos fragmentos de tecidos coletados em feiras e mercados de pulgas em Berlim une diferentes texturas, como tecidos brocados para roupas de festa e estofados antigos, com diferentes densidades e cores/estampas. Os fragmentos foram costurados entre si formando uma assemblage, aproximando-se menos da ideia de figurino do que de um objeto têxtil.

0 estêncil estampado na peça com tinta spray - técnica usada como pichação de palavras de protesto nas ruas e na criação de grafites em fachadas urbanas - é tomado como um ato de inscrição sobre a peça, inaugurando, através da própria palavra, o ato. No processo que aqui analisamos, a palavra INVENCCÃO sobre o tecido alude à criação de algo imprevisto, inédito. 0 estêncil é usado para desenhar nas paredes, mas também reverbera aqui como estampa para a peça, borrando os limites entre superfície, corpo e espaço, expandido a linguagem do fazer e seus instrumentos.

\section{FIGURA 4 - INDUMENTÁRIA/ OBRA TÊXTIL CONFECCIONADA NO ATELIÊ DA UAP, EM COTIA/SP}

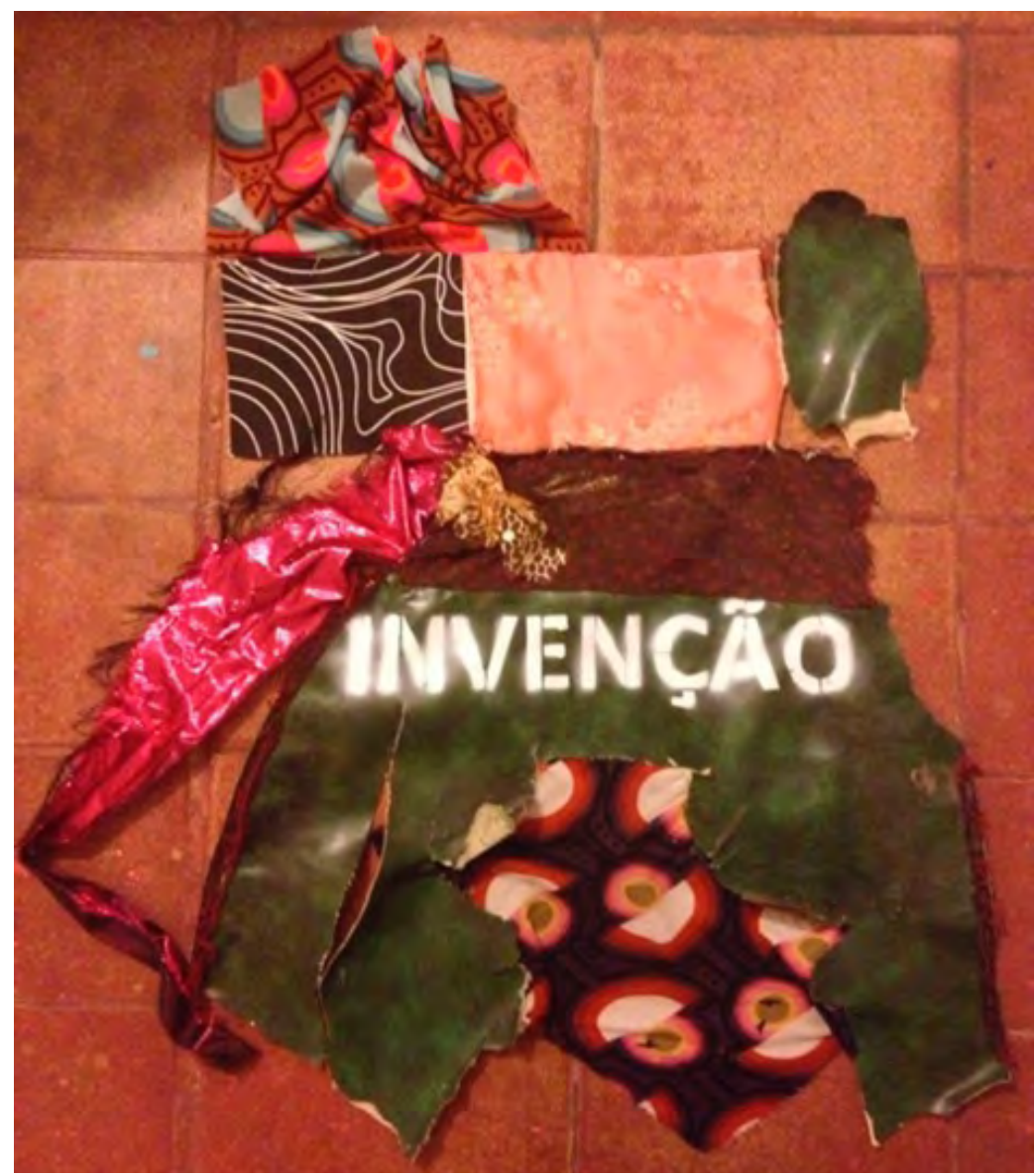

FONTE: REBOUÇAS, Renato Bolelli. Roupa invenção. 1 fotografia. 2014.

Em 2014, Cardoso realiza residência artística na sede da UAP, trazendo para a imersão junto ao coletivo as máscaras e adereços da série Upcycling Dream. Os fragmentos coletados e selecionados no ateliê em Cotia, que foram enviados para Berlim, retornam em novo formato, em busca de movimento, uso, animação, vida. Despertam. Assim, a partir da espontaneidade das ações artísticas efêmeras, deu-se a junção dos elementos que constituem a performance 
(figura 5): a máscara e a veste com o inscrito INVENÇÃO, ambos com o mesmo tecido, criados em diferentes contextos (São Paulo e Berlim), acabam por configurar um conjunto. Para a composição desta imagem, são incluídos dois malotes oficiais da Secretaria de Cultura da cidade de São Paulo contendo projetos para avaliação referentes a um edital municipal, que estavam sob a guarda de um dos artistas no período, pois integrante da comissão avaliadora do edital. Uma nova camada é apresentada ao conjunto, redirecionando seu resultado (sempre provisório).

Deste modo, a figura construída sob o corpo de Bolelli Rebouças foi sendo composta organicamente, e recebeu ainda a colaboração dos artistas Kabila Aruanda e Bukuritós Aruanda, do coletivo UAP, além da documentação da fotógrafa brasileira radicada em Berlim Andrea Lavezzaro, que também participou da residência, propondo durante a performance sugestões para locações e para a construção de situações. A imagem criada pelo grupo, condensada nesta figura corporal, recebeu, portanto, diversas camadas de materiais, significados e intenções. A materialidade das peças, mais do que a noção de personagem ou cena, foi determinante para a composição, articulando texturas, cores, volumes em estranhamentos estéticos. Na rua de terra batida da zona rural onde se localiza a UAP, aconteceu, em alguns minutos, a performance; surge então INVENÇÃO, surpreendendo o próprio grupo, tomada como uma ação pensada inicialmente para a fotografia, e que seguiu se desdobrando em outras imagens e camadas, como veremos.

Qual imaginário cada artista possuía durante as proposições e após estas? Quais as relações possíveis entre arquivos e repertórios individuais e coletivos e como traduzi-los? E ainda: como operar num processo em constante movimento, no qual todas as bases de criação encontram-se disponíveis para a transformação?

\section{FIGURA 5 - RENATO BOLELLI REBOUÇAS EM PERFORMANCE REGISTRADA NA UAP, DURANTE RESIDÊNCIA ARTÍSTICA COLETIVA REALIZADA EM 2014}

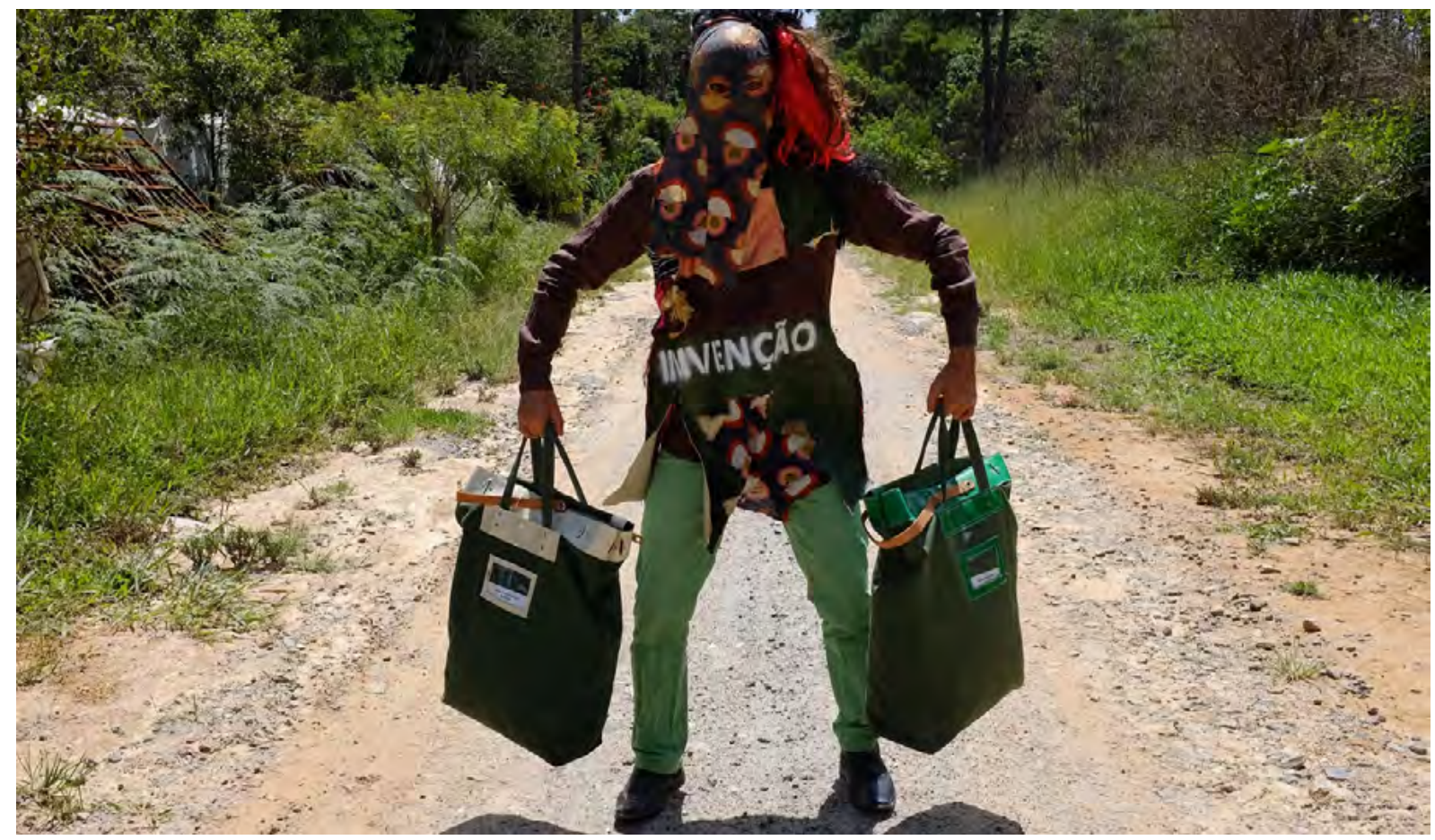

FONTE: LAVEZZARO, Andrea. 0 homem que carrega malotes. 1 fotografia. 2014. 
O caminho dos materiais se explicita, portanto, dando luz às peças que foram reinseridas e trabalhadas manualmente e, posteriormente, retornaram como performance. Após a fotografia, a imagem foi manipulada pelo designer gráfico Marx Deganelli a partir da concepção de Kabila Aruanda (figura 6), deslocando novamente o contexto do corpo-performance e instalando-o numa paisagem referente a uma manifestação ocorrida no centro da cidade de São Paulo no ano de 2014, início de um complexo processo político que resultou na saída da presidenta Dilma Roussef e a ascensão de um governo de extrema direita no Brasil.

Mais uma vez, a surpresa diante de uma nova camada apresentada atualiza a imagem e catapulta-a do rural ao urbano. 0 possível contraste existente anteriormente daquela presença indefinida e amorfa no ambiente interiorano, agora potencializa-se inserida no conflito urbano, em cena épica. Diferentes leituras se abriram neste momento entre os participantes e receptores, gerando inúmeras discussões e avaliações do novo contexto. Tratava-se, claramente, de um combatente, porém, não se definiu de que lado estava, e com qual propósito. É, portanto, nesta indefinição que reside o enigma desta imagem.

FIGURA 6 - IMAGEM RECONTEXTUALIZADA A PARTIR DE INTERVENÇÃO GRÁFICA. CONCEPÇÃO DE KABILA ARUANDA E ARTE GRÁFICA DE MARX DEGANELLI

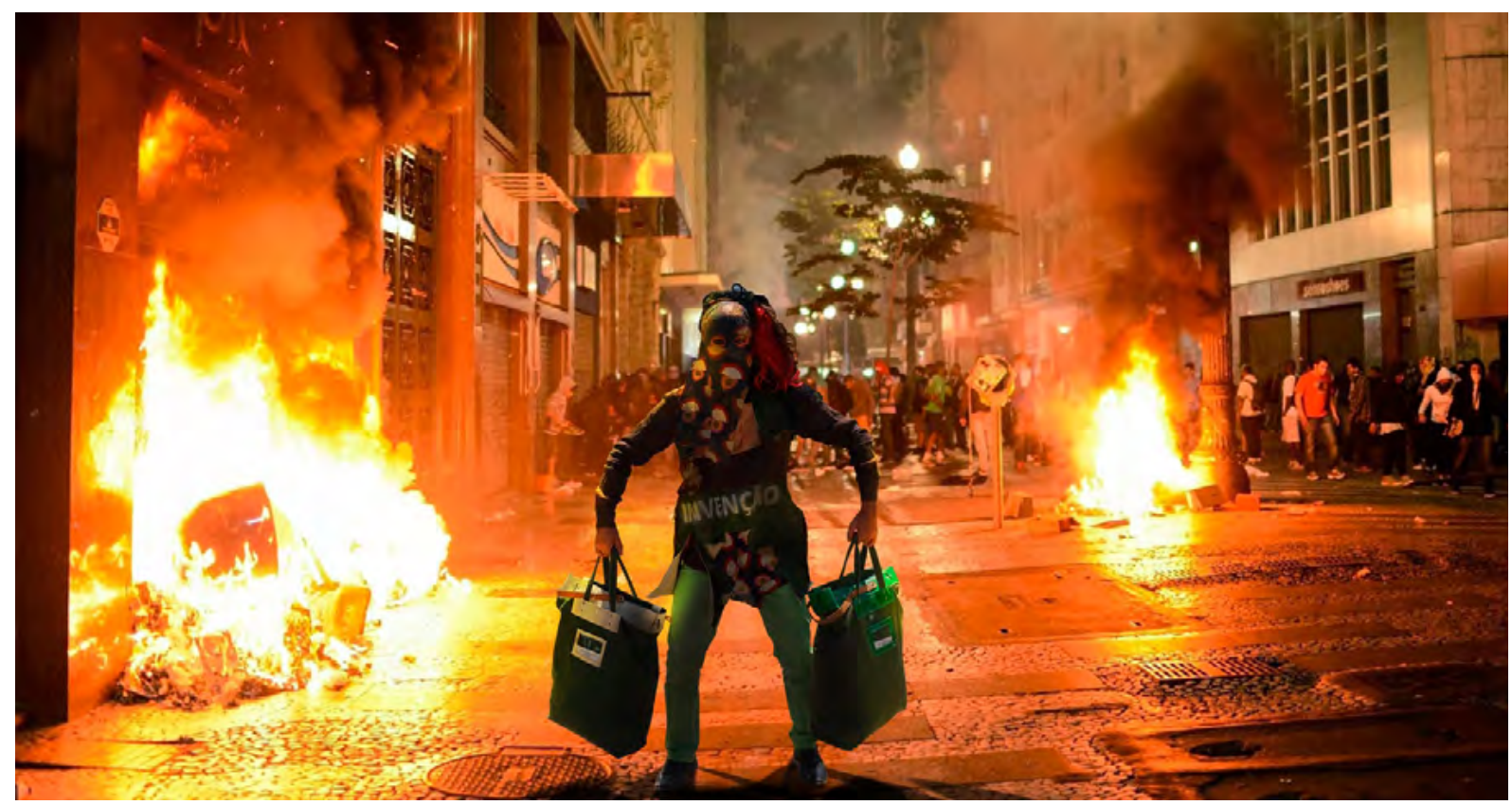

FONTE: ARUANDA, Kabila; DEGANELLI, Marx. INVENÇÃO - Vista a sua existência. Obra resultado de processo de criação coletivo, 2015.

Acompanhando esta trajetória, os materiais - fragmentos coletados numa eterna guerrilha - retornam de outro modo às ruas, reconectando-se à sua origem através de camadas imprevistas. 0 que aqui chamamos de cena expandida poderia ser considerado como performance, como se o enquadramento da imagem fosse se distanciando a cada nova etapa e explicitando seu entorno. Assim, a imagem ganha novos contornos, assim como a significação da figura criada. Após a finalização da nova composição, a imagem foi impressa em papel no 
formato de lambe-lambe, em grande dimensão, e aplicada nos espaços reais da cidade. Mais uma vez, a cidade convida ao retorno e a ideia de guerrilha se presentifica durante a ação de aplicação dos lambe-lambes no espaço urbano. 0 acaso do encontro dos materiais somado à mão que transforma e veste o corpo em ação, gerou inúmeras situações que, ao final, se decompõem, dissolvendo-se no tempo e no movimento constante da cidade.

A criação coletiva instaura campos para uma cena contemporânea expandida em processos híbridos e complexos, na qual é possível acessar dimensões da imaginação e acionar dispositivos para ações performáticas. São processos artísticos com base na troca, participativos, sem autoria definida, que evoluem em intensidade na medida que cada criador expõe suas imaginações e (in)tensões a partir do material, intuitivamente. Trata-se, como sugere Telese (2017, p. 213), de "mudar o foco da cena, sair do teatro e ir para a cena aleatória que acontece da efemeridade e da desconstrução gestada no próprio processo criativo da cena em constante work in progress". Ir adiante, expandir a cena, explodi-la, tomá-la a partir de um zoom out e seus fragmentos: neste sentido, fazer torna-se performance e "cena", dá-se no corpo a corpo, guerrilha.

0 trabalho com fragmentos de materiais inverte, portanto, o procedimento de criação baseado no desenho como concepção/idealização, pois geralmente carrega sua(s) história(s). Assim, o relacionamento com os tecidos traz à tona questões como o tempo, a memória e o uso, dado às suas condições materiais, às marcas neles deixadas por situações diversas, assim como a imaginação de possíveis usos anteriores (quem utilizou esta roupa, quem comprou este tecido, com qual intenção, quando, qual sua origem etc.). 0 tecido antigo e descartado, ao ser reinserido toma corpo, apresenta uma potência de mover ações, porque emana uma energia que é viva, objeto vivo, decadência exaltada em reutilização, agindo intuitivamente sobre o próprio material e na percepção dos criadores. Abre, portanto, novas configurações, novas subjetividades, novas possibilidades.

Os fragmentos que se sobrepõem em cada etapa do trabalho instauram uma fricção entre o corpo, a matéria e o lugar e assim, como afirma Caballero (2011, p. 186), “o acontecimento e a prática tomam o lugar do objeto artístico". Tomando o processo como uma arte performativa da presença, em que o fazer ganha sentido e torna-se parte da obra, aqui as "ações estéticas emergem entre acontecimentos cidadãos e como rituais carnavalescos da sociedade civil, como 'instrumentos de cidadania' dionisíaca” (CABALLERO, 2011, p. 186). Esta perspectiva abre-se, assim, para uma noção de matéria vibrante, por meio da qual Barad (2012, p. 59), em sua defesa pelo conceito de Novo Materialismo (New Materialism), acredita que "o material sente, converge, sofre, deseja, anseia e recorda", porque "sentir, desejar e experimentar não são características singulares ou capacidades apenas da consciência humana"*

\section{Vista sua Existência: plataforma de criação}

Vista sua Existência, que deu origem ao processo de INVENÇÃO, como apresentado anteriormente, é um projeto realizado pela Usina da Alegria Planetária (Uap), uma plataforma de pesquisa e criação que, desde 2010, propõe a troca livre entre artistas, em múltiplos

\footnotetext{
${ }^{4}$ Tradução nossa para: "feeling, desiring and experiencing are not singular characteristics or capacities of human consciousness. Matter feels, converses, suffers, desires, yearns and remembers".
} 
formatos, com base na transdisciplinaridade, na experimentação de linguagens e na reinserção de materiais, indivíduos e seu entorno. É integrada por um coletivo formado por artistas plásticos e visuais, arquitetos, cenógrafos, figurinistas, produtores, músicos, cineastas, educadores e pesquisadores, cujo núcleo principal é formado pelo figurinista e estilista Kabila Aruanda, o diretor de arte Renato Bolelli Rebouças, o artista multimeios Bukuritós Aruanda, a museóloga Giselle Peixe e a diretora de arte e figurinista Vivianne Kiritani. 0 coletivo desenvolve e difunde ações interessadas na cultura material contemporânea, seus processos de produção, consumo e descarte e sua ressignificação, as relações entre os diferentes agentes dos processos criativos e a performance como linguagem. Sua sede, deslocada da região metropolitana, contribui com a sensibilização para o modo orgânico de viver e se relacionar com as pessoas, com o ambiente natural e seus ciclos.

A UAP funciona como um agente articulador para o desenvolvimento de práticas artísticas, oferecendo aos participantes repertório estético, sensorial e técnico. Como um ateliê transdisciplinar, estimula a criatividade como uma experiência de liberdade. 0 espaço físico propõe uma dinâmica de trabalho livre, deixando à mostra materiais, objetos e maquinários, a fim de propor novos processos de criação a partir de pesquisa experimental. Esta prática de trabalho construiu uma metodologia transdisciplinar que é aplicada em diferentes projetos, estimulando a expressão individual e seus riscos a favor de uma estética interessada na participação e no fazer coletivo. 0 interesse se dá em promover um espaço de experimentação e discussão deslocado da cidade, onde a imersão junto à natureza/ao rural possa oferecer alternativas à produção contemporânea.

Vivenciar este modo de vida proposto pelo coletivo, compartilhado entre artistas e não artistas, permite recriar tradições através de experiências integradas ao cotidiano, criando ferramentas mais eficazes e apreendendo pontos de vista mais amplos sobre as transformações em curso no campo sociocultural, antropológico e ambiental. Assim, desde 2012 o Programa de Residência Artística da UAP recebe artistas brasileiros e estrangeiros para visitas, práticas compartilhadas e imersões, promovendo a interação entre o fazer e a construção de linguagem, incentivando processos que nem sempre se ajustam às estruturas existentes e às configurações e fronteiras rígidas das áreas reconhecidas de expressão artística.

Como plataforma de pesquisa, a UAP toma o processo criativo como território para vivenciar experiências envolvendo ações ritualizadas do corpo, espaço e tempo. Inclui uma diversidade de práticas, fazeres e técnicas a partir do estímulo da criatividade e percepção de si e seu entorno. Neste sentido, um fator determinante para o desenvolvimento destes processos é a questão afetiva, que se dá através de uma troca sensível de experiências, e toma a criação compartilhada uma ação imersiva e contínua. Assim, este percurso une o fazer manual, o corpo performativo, a ação fotográfica e, ainda, a manipulação digital da imagem, até chegar à imagem impressa colada nas paredes que, por sua vez, segue em processo, decompondo-se com o tempo, cumprindo sua efemeridade.

\section{Do corpo ao espaço ao corpo}

Os parangolés de Hélio Oiticica anunciaram, na década de 60, uma mudança radical nas artes visuais e performáticas brasileiras e mundiais, através da invenção de uma roupa-obra, que "não era para ser vestida e sim in-corporada" (OITICICA, 1986). Em movimento, 
os neoconcretistas no Brasil propunham o fim da pintura e da escultura para uma arte integrada ao corpo social. Assim afirma Oiticica em trecho do filme H.O., (1979) de Ivan Cardoso:

\begin{abstract}
o Parangolé não era uma coisa para ser posta no corpo e para ser exibida, a experiência da pessoa que veste e da pessoa que está fora vendo a outra vestir, ou das que vestem simultaneamente a coisa, são experiências simultâneas, multiexperiências. Não se trata do corpo como um suporte para a obra, pelo contrário, é $a$ total incorporação, a incorporação da obra no corpo e do corpo na obra. Eu chamo de in, traço de união, corporação (H.O., 1979, grifo nosso).
\end{abstract}

Atualmente vivenciamos uma nova dissolução das fronteiras nas artes que reverberam dos pensamentos radicais que moveram práticas tidas como transgressoras do século passado. Ao afirmar a matéria como o elemento que move uma ação, aciona-se assim um corpo performático que se coloca em situação, em ação direta, que se constitui em imagens de potências extraordinárias, sequenciais, na interseção entre o corpo, o lugar, e algo que tira esse corpo da realidade. Podemos chamar este algo de performatividade.

0 ato de vestir cria, portanto, um dispositivo que inaugura um campo aberto para a imaginação, a memória e a presença do corpo, utópico e político, pois em constante situação, em ação. 0 figurino/roupa torna-se um dos possíveis elementos de ruptura e intervenção nesse corpo político, "real", em performance. Aqui, adereços, peças têxteis e de roupas se misturam, assim como todos os elementos que compõem nossa aparência.

[...] a máscara, a tatuagem, o enfeite colocam o corpo em outro espaço, o fazem entrar em um lugar que não tem lugar diretamente no mundo, fazem desse corpo um fragmento de um espaço imaginário, que entra em comunicação com o universo das divindades ou com o universo do outro (FOUCAULT, 2013, p. 12).

Neste sentido, as figuras imaginárias criadas nessas ações acessam outras camadas de intersecções e utopias, pessoais e coletivas, e servem como uma alavanca para criações performáticas, efêmeras, registradas em fotografias e formalizadas como performances. Cada elemento que ali se transforma, carrega sua história, pois não foi comprado e sim reinserido; e também atua a partir do "acaso" do fazer, sem um projeto pré-estabelecido, instaurando a fricção dinâmica entre o material, as mãos, o corpo e o lugar. Acontecimentos.

Em vez de fornecer produtos ao mercado, a arte participativa canaliza o capital simbólico da arte para a mudança social construtiva. Dada esta política declarada e o empenho que mobiliza este trabalho, é tentador sugerir que possivelmente 
esta arte crie a vanguarda que temos hoje: artistas que encaram as situações sociais como um projeto desmaterializado, antimercado, politicamente comprometido, para corresponder ao apelo da vanguarda no sentido de tornar a arte uma parte mais vital da vida (BISHOP, 2017, p. 77).

A partir da investigação deste processo à luz da prática de Hélio Oiticica e das provocações de Claire Bishop, questiona-se: como temos nos relacionado com nossa própria imagem e as múltiplas identidades que nos habitam? Quais as relações possíveis, reais e imaginadas, entre corpo, subjetividade e participação social? Se é sempre o corpo que veste - seja uma roupa, um figurino, um parangolé ou uma obra - e vive suas experiências condensando as camadas reais e construídas, seria possível pensar que o corpo, instrumento relacional fundamental ao ser social, carrega consigo uma dimensão política obrigatória. De acordo com Michel Foucault:

é o próprio corpo que volta contra si seu poder utópico e faz entrar todo o espaço do religioso e do sagrado, todo o espaço do outro mundo, todo o espaço do contra-mundo [...]. Então, o corpo, em sua materialidade, em sua carne, seria como o produtor de suas próprias fantasias (FOUCAULT, 2013, p. 13).

Assim, a descoberta do corpo atravessado por experiências estéticas, vestido de subjetividades, permite que se discutam signos, repertórios e padrões sociais instaurados e consolidados, regidos pela família, pela política, pela religião, pelo consumo. Vestir nossa própria existência aproxima-nos de um sujeito ativo e presente, de uma realização de sujeito social que compartilha as diversidades, a autonomia e a liberdade.

0 fazer artístico como um processo livre abre um campo para a experimentação no qual o material inicia o movimento de criação e as possíveis personagens, dando corpo a figuras imaginárias, surgem sem um projeto estabelecido e muitas vezes sem uma função definitiva. Porém, se toda ficção se torna real no corpo, a imagem aqui construída (inventada) torna-se real à medida em que é vivida e compartilhada.

0 corpo, portanto, coloca-se no espaço, na rua, compreende-se por relação. Assim, propomos ao final deste percurso reinscrever estes corpos na cidade, em escala ampliada. Ao ganhar muros, fachadas e empenas para a colagem dos lambe-lambes, o corpo (re) transformado em imagem retorna ao espaço público, garante seu lugar e, assim, material e imaterial, retorna à paisagem. As "incorporações" realizadas ao vestir imagens - compreendidas como experiências da cidade inscritas no corpo - ampliam-se em dimensão coletiva através de experiências corporais agora inscritas nas cidades. 0 corpo-imagem ganha densidade e corporifica-se, expande-se, dialoga com os passantes, dá-se a ver, gera reações, dá continuidade ao processo de guerrilha, está disponível à luta, à afirmação de sua identidade múltipla, à não normatização. 
FIGURA 7 - LAMBE-LAMBE APLICADO EM BERLIM DURANTE INTERVENÇÃO DE RENATO BOLELLI REBOUÇAS E BUKURITÓS ARUANDA

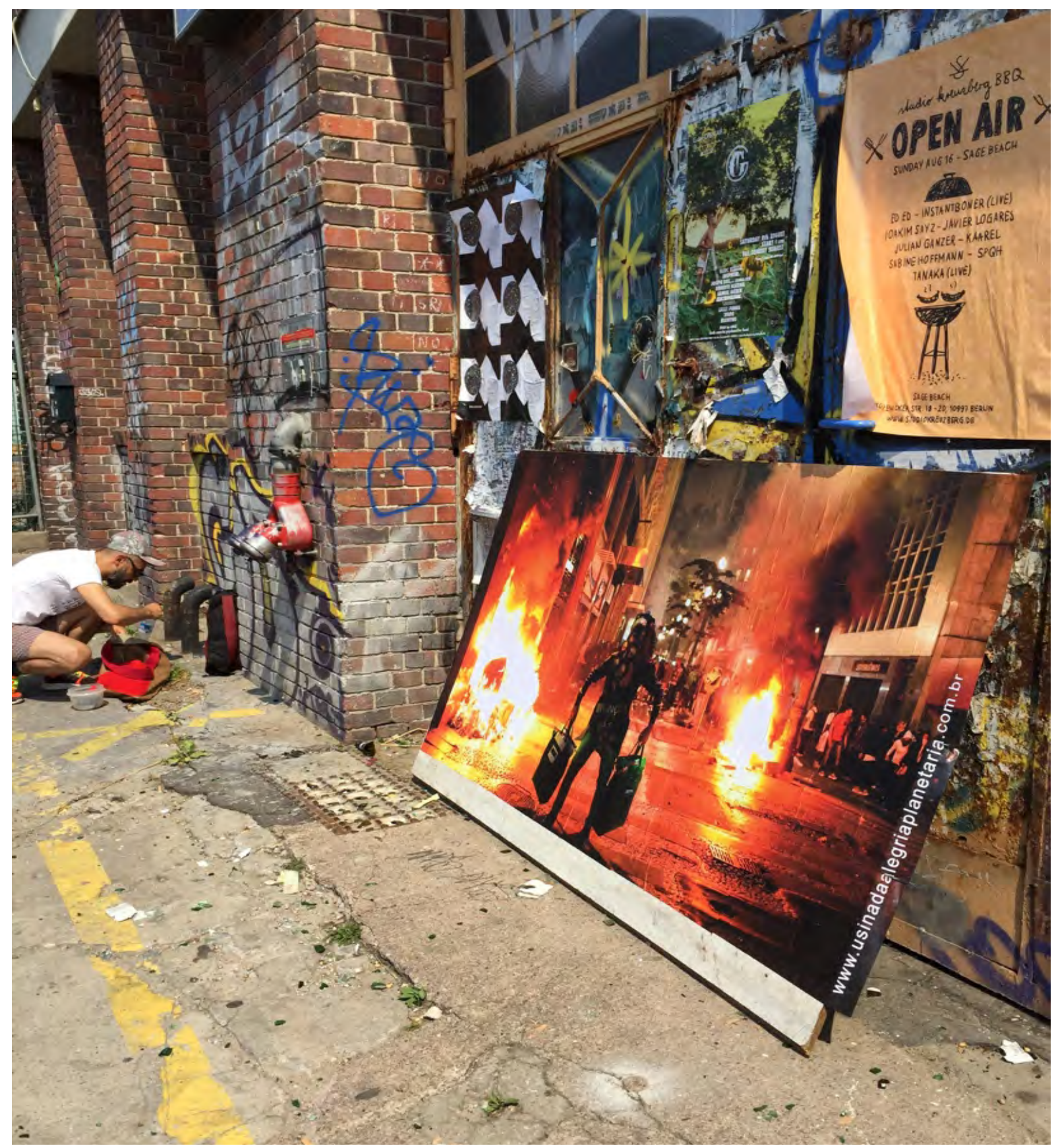

FONTE: ARUANDA, Bukuritós. Lambe-lambe INVENÇÃo em Berlim. 1 fotografia. 2015.

As ações de instalação dos lambe-lambes foram realizadas primeiramente em Berlim, em 2015, organizadas por Bolelli e Bukuritós Aruanda, em parceria com Lavezzaro. Os participantes, ocupando diferentes papéis e responsabilidades durante o processo, agem 
também em camadas, de modo instintivo, desdobrando seu fazer de acordo com os resultados anteriores. Assim como os materiais, as imagens circulam e retornam. A máscara criada em Berlim é instalada sobre papel em outro território da cidade, agora no bairro de Kreuzberg, encarando os passantes num tipo de luta armada, empreendida por um movimento de tempos, ocupando seu espaço de modo não institucional, tático, político.

Outro lambe-lambe foi instalado no ano seguinte na sede da UAP, também em retorno ao processo, reinaugurando sua presença no território rural, sede criativa do projeto. Faz-se interessante pensar estas duas imagens-ações em ambientes opostos, locus inicial da travessia artística, como se de fato quisessem retornar à suas origens, permanecer diante de seus criadores, após empreendida sua jornada coletiva. A fala do corpo da imagem, deste guerrilheiro, é garantida e passa a compor a temporalidade, envelhece lentamente. Agora, em suas casas, podem envelhecer e decompor-se, dissolvem-se diariamente como efemeridades. Cumpridas suas finalidades, iniciam um processo entrópico, a última performance, a figuração do desaparecimento.

\section{FIGURA 8 - LAMBE-LAMBE APLICADO NA SEDE DA UAP DURANTE INTERVENÇÃO DE RENATO BOLELLI REBOUÇAS E BUKURITÓS ARUANDA}

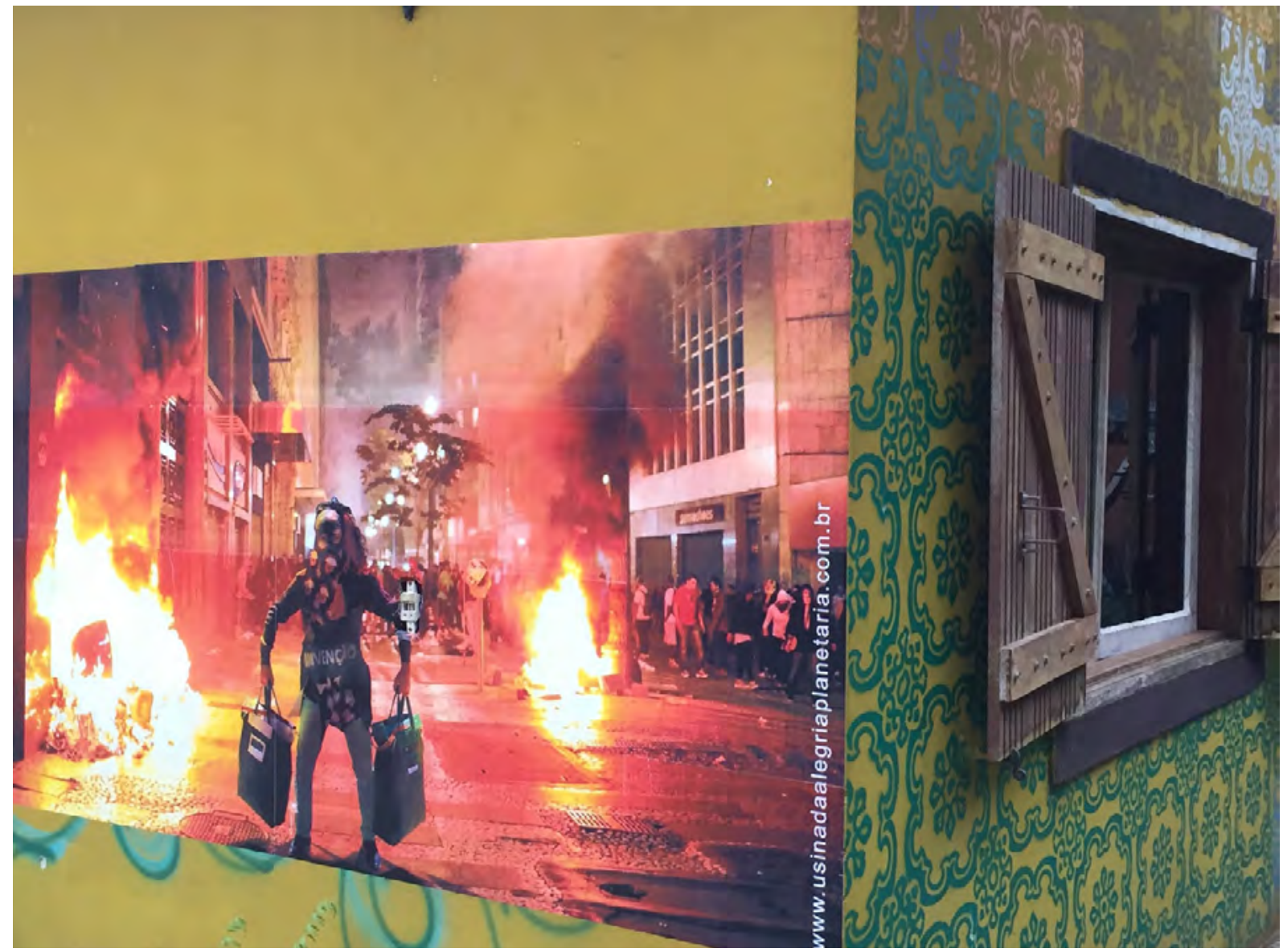

FONTE: REBOUÇAS, Renato Bolelli. Lambe-lambe INVENÇÃo na sede da UAP em Cotia. 1 fotografia. 2016. 


\section{Desdobramentos: Figurino em Ação}

As práticas vividas e compartilhadas no projeto Vista sua Existência, tomadas como um procedimento ou metodologia de trabalho, inspirou e originou outras criações, como o projeto Figurino em Ação. Coordenado por Cardoso, iniciou-se como um curso de figurinos realizado a partir do acervo de materiais da artista (tecidos, peças de roupas, adereços e fragmentos), acumulados durante dez anos e em ação permanente de troca com diferentes parceiros e participantes. Motivada pelo envolvimento em criações coletivas, em processos complexos nos quais é possível acessar outras dimensões da imaginação, a proposta tomou forma a partir do fazer e do envolvimento crescente com ações performáticas, reverberando em diversos formatos, além de cursos e exposições dos resultados.

0 processo busca, em consonância com o percurso anteriormente apresentado, um figurino que não nasce do desenho, mas sim do material, sem design, o figurino sem personagem, sem teatro. Imagens e cenas que nascem do material são transformadas em adornos criados diretamente sobre o corpo e para os corpos. Trata-se de um modo horizontal de criação em que o material e o fazer incitam uma performance na troca entre a matéria, o repertório, as mãos, o corpo, o olho da máquina fotográfica e o imaginário que se instaura durante cada ação.

O trabalho participativo com base na troca, do material para o corpo, do corpo para a obra que volta para o corpo, vira imagem e ocupa espaços em exposição. Assim, emancipa ideias, conecta-se a referências, amplia repertórios com texturas, volumes e escalas. Neste sentido, o corpo político e suas ações caminham contra a corrente da ordem neoliberal do mundo. Nas palavras de Bishop, "mesmo que uma obra de arte não seja diretamente participativa, as referências à comunidade, coletividade (seja esta perdida, seja reconfigurada) e revolução são suficientes para indicar uma distância crucial relativamente à nova ordem neoliberal do mundo (BISHOP, 2017, p. 76).

0 termo upcycling é utilizado para definir o processo e reconfigura o material em novo corpo e novas ações. Desta maneira, o acervo de Figurino em Ação é ativo e nele se integram também elementos outros, como partes de figurinos já trabalhados, mas que retornam à condição de material e se refazem. Aqui, tudo pode ser de novo e de novo transformado.

0 fazer manual inspira a existência e a história sensível dos materiais, que acessam uma memória fora do tempo. 0 corpo mascarado, adornado, toma a potência de um sonho. É exatamente nesse ponto que a participação do outro nesse processo esbarra na ideia de inacabado, de um momento de ação fora da realidade, atingindo narrativas fora do espaço e do imaginário narrativo convencional, adentrando o fantástico. Revoluções.

Estes processos artísticos com base na troca, participativos, em autorias compartilhadas entre artistas e os próprios materiais, evoluem em intensidade à medida em que cada criador expõe suas imaginações. Por isso, a potência das ações desdobradas que ele promove acaba por transformar-se em atos e ativar esferas sociais e espirituais atingidas através da arte. Figurino em Ação explora o universo onírico contido em todo ser humano, e convida seus participantes a materializar esta dimensão. 
É difícil revivificar os próprios sonhos, construir a partir do heterogêneo, desenvolver a arte de reinventar de outro modo a própria vida, até então mutilada. É por isso que engendramos levantes sem-fim. Sem-fim porque com muita frequência tudo se repete, tudo fracassa; tudo fracassa nas praias do conformismo ou contra as falésias dos serviços de ordem. 0 recomeçar, porém, também é sem-fim (DIDI-HUBERMAN, 2017).

Este processo de ampliação da percepção se dá numa criação cênica expandida, numa narrativa sem palavras, sem estrutura predefinida, partindo apenas de um corpo em constante transformação e ativo, inquieto, potencializado pelo imaginário que se amplifica para criar algo coletivo e, portanto, político. Que figuras, imagens, universos e seres habitam nossas paisagens internas? É no desinteresse pela função que se encontra o caminho percorrido:

Assim, a criação de um novo uso só é possível ao homem se ele desativar o velho uso, tornando-o inoperante. Toda tentativa de Eu, do elemento pessoal, de se apropriar de Genius, de obrigá-lo a assinar seu nome, está necessariamente destinada a fracassar. Nascem daí a pertinência e o sucesso de operações irônicas como aquelas das vanguardas, nas quais a presença de Genius é testemunhada des-criando, destruindo a obra (AGAMBEN, 2017, p. 18).

A troca de experiências livres é aqui também tomada como elemento de fricção, quando a indumentária e o ato de vestir se expandem para ações políticas de ativação social e podem ser verificadas tanto no campo artístico do teatro e da performance como nas artes visuais contemporânea. As linguagens novamente se hibridizam e misturam, sobrepõem-se, operam pela lógica da assemblage.

Nesse processo de sobreposições não racionais de elementos imaginados, as manualidades que transformam o material transformam também o corpo, que se transforma em imagem. A imagem refletida perde sua substância com o adorno, o mascaramento. Através do enquadramento e da pose da performance pensada para a fotografia, o jogo entre o corpo, o adorno e a imagem se forma. Por isso, sua operação é dinâmica e se adapta a diferentes formatos e circunstâncias. $\mathrm{O}$ fazer com o outro abre um campo vasto de possibilidades. É preciso saber falar, é preciso saber ouvir, é preciso saber filtrar e é preciso agir autonomamente no coletivo.

Portanto, a criação horizontal busca instaurar ações em meio ao caos e à diversidade. Neste percurso, aceitando o processo como resultado, o fazer comungado na vivência coletiva se afirma como conhecimento. Entendido como "composição de heterogêneos", o processo de "tornar as formas líquidas", mutáveis, busca "tirar um cosmos do caos, e dar a ele um lugar estável” (LAPOUJADE, 2017, p. 84). 
Um indivíduo existe neste mundo; ele existe como corpo, existe como "psiquismo", mas também existe como reflexo em um espelho, como tema, ideia ou lembrança no espírito do outro, tantas maneiras de existir em outros planos. Nesse sentido, os seres são realidades plurimodais, multimodais; e aquilo que chamamos de mundo é, de fato, o lugar de vários "intermundos", de um emaranhado de planos (LAPOUJADE, 2017, p. 14-15).

Os processos de INVENÇÃO, Vista sua Existência e Figurino em Ação aqui apresentados, desdobram-se entre si como um único percurso de criação, contínuo, complexo e coletivo. Como um ato de guerrilha, torna-se ele próprio ação, performance, acontecimento. Estas práticas têm sido investigadas como alternativas ao modo de produção tradicional, invertendo lógicas e procedimentos na busca de alcançar outras dimensões possíveis para o ato criativo.

\section{Referências}

AGAMBEN, Giorgio. Profanações. Tradução Selvino J. Assmann. São Paulo: Boitempo, 2017.

BARAD, Karen. Interview with Karen Barad. In: DOLPHIN, Rick; TUIN, Iris van der. New Materialism: Interviews \& Cartographies. Ann Arbor: MPublishing - University of Michigan Library, 2012. Disponível em: http://openhumanitiespress.org/books/download/Dolphijnvan-der-Tuin_2013_New-Materialism.pdf. Acesso em: 12 jul. 2019.

BISHOP, Claire. A viragem cultural: o mal-estar na colaboração. Tradução Luis Leitão. In: PAIS, Ana (org.). Performance na esfera pública. Lisboa: Orfeu Negro, 2017.

CABALLERO, Ileana Diéguez. Cenários Liminares: teatralidades, performances e política. Tradução Luis Alberto Alonso e Angela Reis. Uberlândia: Edufu, 2011.

DIDI-HUBERMAN, Georges. Imagens e sons como forma de luta. Tradução Edgard de Assis Caravalho e Mariza Perassi Bosco. São Paulo: Sesc Pinheiros, 2017. Disponível em: https://www. sescsp.org.br/online/artigo/12580_IMAGENS+E+SONS+COMO+FORMA+DE+LUTA+ENSAIO+DE+ GEORGES + DIDIHUBERMAN. Acesso em: 12 jul. 2019.

FOUCAULT, Michael. 0 corpo utópico, as heterotopias. Tradução Salma Tannus Muchail. São Paulo: Editora N-1, 2013. 
H.O. Direção: Ivan Cardoso. Produção: Fernando Carvalho, Ivan Cardoso. Intérpretes: Caetano Veloso, Carlinhos do Pandeiro, Ferreira Gullar, Hélio Oiticica, Lygia Clark, Nildo da Mangueira, Nininha, Waly Salomão. Roteiro: Ivan Cardoso. Rio de Janeiro: 1979. 13 min., 35 mm. Disponível em: http://portacurtas.org.br/filme/?name=ho. Acesso em: 12 jul. 2019.

LAPOUJADE, David. As Existências Mínimas. Tradução Hortencia Santos Lencastre. São Paulo: N-1, 2017.

OITICICA, Hélio. Aspiro ao grande labirinto. Rio de Janeiro: Rocco, 1986.

TELESE,SilviaFernandes.Experiênciasdeperformatividadesnacenabrasileiracontemporânea. In: DESGRANGES, Flávio; SIMÕES, Giuliana. $\mathbf{O}$ ato do espectador: perspectivas artísticas e pedagógicas. São Paulo: Ed. Hucitec, 2017. 